\title{
Asthma severity and medical resource utilisation
}

\author{
L. Antonicelli*, C. Bucca ${ }^{\#}$, M. Neri ${ }^{\top}$, F. De Benedetto ${ }^{+}$, P. Sabbatani ${ }^{\S}$, F. Bonifazi*, H-G. Eichler ${ }^{f, * *}$, \\ Q. Zhang**, D.D. Yin**
}

Asthma severity and medical resource utilisation. L. Antonicelli, C. Bucca, M. Neri, F. De Benedetto, P. Sabbatani, F. Bonifazi, H-G. Eichler, Q. Zhang, D.D. Yin. C)ERS Journals Ltd 2004.

ABSTRACT: Asthma represents a growing public health problem and the cost of asthma has been rising in many countries. The aim of this study was to estimate the direct and indirect cost of asthma among adult patients in Italy, and to assess the relationship between healthcare resource use and asthma severity according to the Global Initiative for Asthma (GINA) classification system.

A multicentre cross-sectional study was conducted in 16 Italian hospital-based specialised asthma clinics. Data collection was based on self-administered questionnaires and took place during the period May 1-November 30, 1999, and 500 consecutive patients with asthma, aged 18-55 yrs, were enrolled during regularly scheduled visits. Direct costs (drugs, physician visits, emergency service use and hospitalisation), indirect costs (loss of paid workdays) and total costs were determined in euros $(€)$ for 1999.

Patients with more severe disease, as classified by the GINA guideline, exhibited more night-time and daytime symptoms and were more limited in performing normal daily activities. The mean total cost of asthma per patient per year was estimated to be $€ 1,260$; drug costs accounted for $16 \%$, physician costs $12 \%$, emergency service and hospitalisation costs $20 \%$ and indirect costs $52 \%$ of the mean cost. Stratified by severity, the total annual cost per patient amounted to $€ 720, € 1,046, € 1,535$ and $€ 3,328$ for patients with intermittent, mild persistent, moderate persistent and severe persistent asthma, respectively.

Asthma severity, as determined by the Global Initiative for Asthma classification, is significantly associated with symptoms, limitations in normal daily activities, asthmarelated medical resource utilisation and both direct and indirect costs. Asthma control is not only a clinical but also an economic imperative.

Eur Respir J 2004; 23: 723-729.
*Dept of Respiratory and Allergic Diseases, Umberto I Hospital, Ancona, \#Dept of Biomedical Sciences and Human Oncology, University of Turin, Turin, "Division of Pulmonary Disease, Institute for Care and Research, Scientific Institute of Rehabilitation, Salvatore Maugeri Foundation, Tradate, Division of Pulmonary Disease, General Hospital Chieti, Chieti, and ${ }^{8}$ Division of Pulmonary Disease, Morgagni Hospital, Forli, Italy. ${ }^{f}$ Dept of Clinical Pharmacology, Vienna University Medical School, Vienna, Austria. ${ }^{* *}$ Outcomes Research, Merck \& Co., Whitehouse Station, NJ, USA.

Correspondence: D.D. Yin, Outcomes Research, Merck \& Co., Inc., WS2E-60, One Merck Drive, P.O. Box 100, Whitehouse Station, NJ 08889-0100, USA.

Fax: 19087351688

E-mail: donald_yin@merck.com

Keywords: Asthma, cost of illness, Global Initiative for Asthma guidelines, health economics, healthcare utilisation, severity

Received: January 142003

Accepted after revision: December 152003

This study was supported by a grant from Merck \& Co., Inc., Whitehouse Station, NJ, USA.
Asthma is a chronic episodic disease, characterised by acute symptomatic episodes of varying severity, occasionally nearfatal or fatal, that affects $\sim 3-5 \%$ of adults in the general population. Since the 1970 s, the frequency and severity of asthma has increased in a considerable number of countries, in both children and adults [1-4]. Not surprisingly, the cost of asthma has also been rising [2, 3, 5], and has been shown to be strongly associated with the severity of the disease [6, 7]. However, cost-of-illness data for asthma cannot be directly extrapolated from one country to another because there is considerable variation in the total mean annual cost per affected person by country [6]. Although some of this reported variation may be due to methodological differences, direct international comparisons of asthma care and resource utilisation have shown real and substantial variations between countries in treatment practice, drug prescription rates and patient compliance $[8,9]$.

There is evidence that utilisation of anti-inflammatory drugs in asthma therapy in Italy was poor until the beginning of the 1990s [10], but appears to have improved since then. This is indicated by the increase in the consumption ratio of inhaled corticosteroids to bronchodilators from 0.36 in 1991 to 1.03 in 2000 [11]. However, at the time when the present study was planned, little information was available regarding utilisation of other healthcare resources or the cost of asthma in Italy. Health economic analyses are increasingly important in helping to make informed choices in the delivery of care. The aim of the present study was, therefore, to estimate the direct and indirect cost of asthma among adult patients with asthma in Italy. Moreover, the relationship between healthcare resource use and asthma severity according to the Global Initiative for Asthma (GINA) classification system [12] was assessed.

\section{Patients and methods}

\section{Study design and setting}

A multicentre cross-sectional study was conducted in 16 hospital-based specialised asthma clinics chosen from all over Italy, with 125 patients from northern Italy, 225 from central Italy and 150 from southern Italy. The collaborating physicians were allergologists (four centres contributing 175 patients), pulmonologists (nine centres, 250 patients) or internists experienced in asthma care (three centres, 75 
patients). Clinic selection was aimed at representing a broad spectrum of asthma care settings and regions in Italy; specialist centres, rather than general practitioners (GPs), were enrolled to ensure a patient sample encompassing all degrees of severity of asthma.

All data were collected during the period May 1-November 30, 1999. The study protocol provided for consecutive patients to be interviewed during regularly scheduled visits.

\section{Patient selection criteria}

Patients were eligible for inclusion in the present study if they were aged 18-55 yrs, gave informed consent, had a $\geqslant 1-y r$ history of asthma, and were in good mental and physical health (apart from the asthma). Exclusion criteria were: major surgery or transplantation in the preceding 12 months; a history of congestive heart failure, cancer, arthritis or a neurological condition; the presence of a pulmonary disorder other than asthma, including chronic obstructive pulmonary disease (COPD), emphysema and cystic fibrosis; and a smoking history of $>20$ pack-yrs.

The study was planned to include 500 evaluable patients, and recruitment was to be halted at the time when this number was reached.

\section{Data collection}

During the course of a scheduled office visit, patients were invited by their treating physician to participate in the present survey. Those patients willing to take part were asked to complete and hand in a self-administered questionnaire at the end of the office visit. The survey included questions on: sociodemographic data; number of nights waking up because of asthma; number of days with asthma symptoms during the day; number of days with limitations and the extent of these limitations in daily activities during the past 14 days; description of the impact of asthma exacerbations or worsening asthma on sleep and activities during the past 14 days (in accordance with GINA terminology based on the 1995 version [12]; exacerbations were defined as any acute or gradual worsening of asthma, which has been shown to be synonymous with symptoms of worsening asthma [13]); inhaled and oral medication use during the past 14 days and 6 months; GP or specialist visits during the past 6 months; hospitalisation and emergency room visits during the past year; paid and unpaid workday loss per month during the past 1-yr period; effectiveness at paid work; and patient's satisfaction with treatment ( $0-100 \mathrm{~mm}$ visual analogue scale). Different recall periods were chosen to maximise the accuracy of self-reported data for different events.

Physicians were surveyed regarding patients' asthmatic and atopic status, comorbid conditions and most recent prebronchodilator forced expiratory volume in one second (FEV1) result (if available). They were asked to classify patients into one of four different severity levels: intermittent, mild persistent, moderate persistent, and severe persistent, based on the GINA classification system (1995 version) [12]. Consistent with other authors [13], it was observed that the GINA algorithm for classification of asthma severity based on clinical and functional features alone is unsuitable for cross-sectional studies, since the majority of patients are treated. Therefore the specialist was asked to classify patients into one of the four severity categories according to a combination of symptom and FEV1 criteria and the GINA recommendations regarding medication appropriate at each level of severity [12]. Clinical judgment was, therefore, involved in the asthma severity classification only to the extent of allowing the clinicians to overcome the difficulties of GINA guideline application in population studies [13], and in accordance with prior research $[14,15]$. Separate asthma severity levels were determined for the past 14 days and past year.

\section{Valuations and cost analysis}

The cost analysis was performed from a societal perspective. Units of resource consumption were directly obtained from the questionnaires. Utilisation and cost data were extrapolated to a 1-yr period, without adjustment, from the recall periods specified above. For medication use, data from the 14-day recall period were used for extrapolation on the basis of previously conducted research showing that 14-day recall has good predictive properties for annual resource use analysis [16]. Direct and indirect costs were calculated in or adjusted to 1999 Italian lire (ITL) and converted to euros (€1=ITL 1936.27).

As is customary in most pharmacoeconomic analyses, charges were used as a proxy for costs. Unit costs were obtained as follows. Drug costs were taken from the official wholesale drug price list in Italy [17]. Costs for resources utilised were based on the official tariffs of the Italian national health service for ambulatory visits and tests [18], and hospital admissions [19]. Supplemental diagnostic tests that were not subsumed under the cost of outpatient visits or hospitalisation were not valued; however, previous work has shown that these account for only a very small fraction of the cost of asthma $[6,20,21]$.

Analysis of indirect cost was based exclusively on the number of paid workdays lost; the unit value was taken from the previous estimates of DAL NEGRo et al. [22] and BERTO et al. [23]. Unpaid workdays lost and lost productivity at work are reported but were not incorporated in the cost analysis. This was done, in part, because the present instrument for assessing decreased productivity at work has not been adequately assessed.

\section{Statistical analysis}

The Chi-squared test was used to assess associations between asthma severity and categorical outcome variables. A generalised linear model procedure was used to assess the effect of disease severity on continuous outcome variables. In addition, the nonparametric Kruskal-Wallis test was applied when the variable had a skewed distribution. A two-tailed p-value of $<0.05$ was considered significant.

\section{Results}

Of the 547 consecutive patients who met the selection criteria and were invited to participate in the study, 44 patients declined and three questionnaires were not useable. Therefore, 500 patients were available for analysis; 59\% of these were surveyed during their first specialist visit, after first-time referral from GPs, and $41 \%$ were studied during a scheduled follow-up visit. Their mean \pm SD age was $36.6 \pm 10.7 \mathrm{yrs}$ and $57.2 \%$ were female. At the time of survey, $66.4 \%$ of the patients worked for pay. The patients were classified by physicians into one of four mutually exclusive severity classes, in accordance with the GINA guidelines [12]; classifications were performed for the past 14 days and year. The percentages of patients with intermittent, 
mild persistent, moderate persistent and severe persistent asthma were $34.8,26.8,30.6$ and 7.8 during the past 14 days, and $27.2,29.8,37.6$ and 5.4 during the past year, respectively. These two classifications within this cohort were in good overall agreement (weighted kappa $=0.49 ; 95 \%$ confidence interval $0.43-0.55$ ). Only the results of the classification based on a 14-day period are presented here because they are less likely to be affected by recall bias.

Patient characteristics and self-reported symptoms during the past 14 days by severity grade are listed in tables 1 and 2, respectively. There was a significant association between asthma severity and all symptom categories.

Patient-reported medication use during the past 14 days by asthma severity is shown in table 3 .

Patients in the present sample had made, on average, 4.9 GP visits and 4.1 other physician visits during the past year; $15.8 \%$ of them had made one or more visits to emergency departments and $8.2 \%$ had experienced one or more hospitalisations during the past year. The mean number of emergency department visits and hospitalisations were 0.42 and 0.13 , respectively. The patients lost a mean of 6.4 paid workdays and 4.2 unpaid workdays per year. Healthcare resource use and productivity loss during the past year by severity are summarised in tables 4 and 5, respectively. Patients' satisfaction with treatment is also shown in table 5; it must be emphasised, though, that the present instrument for assessing patients' satisfaction with treatment has not been validated in the present setting. Hence, this data must be considered exploratory.

The mean total cost of asthma per patient per year was estimated to be $€ 1,260$, $€ 600(48 \%)$ of which represented direct medical costs and $€ 660(52 \%)$ indirect costs. Stratified by severity, the total annual cost per patient amounted to $€ 720$, $€ 1,046$, $€ 1,535$ and $€ 3,328$ for patients with intermittent, mild persistent, moderate persistent and severe persistent asthma, respectively. Figure 1 shows asthmarelated direct and indirect costs per patient during the past year by asthma severity. Overall, medications costs accounted for $16 \%$, physician costs $12 \%$, emergency service and hospitalisation costs $20 \%$, and indirect costs $52 \%$ of the mean cost per patient per year. When considering direct medical costs only, medications accounted for $33 \%$, physician costs $25 \%$, and emergency service and hospitalisations $42 \%$ of expenses. Figure 2 shows the relationship between asthma severity and total and direct costs.

\section{Discussion}

Results from the present cross-sectional study confirm and extend findings from previous assessments of medical

Table 1.-Baseline patient characteristics by asthma severity grade

\begin{tabular}{lccccc}
\hline & Total & Intermittent & Mild persistent & Moderate persistent & Severe persistent \\
\hline Patients n (\%) & 500 & $174(34.8)$ & $134(26.8)$ & $153(30.6)$ & $39(7.8)$ \\
Age yrs & $36.6 \pm 10.7$ & $34.2 \pm 10.7^{*}$ & $36.0 \pm 9.8^{*}$,\# & $38.5 \pm 10.5^{\#}$ & $42.0 \pm 11.6^{\bullet}$ \\
Females \% & 57.2 & 56.3 & 53.7 & 56.9 & 74.4 \\
Comorbid conditions \% & 69.6 & 75.3 & 71.6 & 63.4 & 61.5 \\
$\quad$ Rhinitis & 57.0 & $64.9^{+}$ & $59.7^{+}$ & $24.0^{+}$ & $3.9^{+}$ \\
Sinusitis & 21.2 & 18.4 & 20.2 & 14.4 & 25.6 \\
Nasal polyps/aspirin intolerance & 13.0 & 9.8 & 14.2 & $76 \pm 19$ & $57 \pm 20$ \\
FEV1 \% pred & & $91 \pm 15$ & $87 \pm 17$ & & 18.0 \\
\hline
\end{tabular}

Data are presented as mean \pm SD unless otherwise indicated. FEV1: forced expiratory volume in one second; \% pred: per cent predicted. $\S$ : data available for 314 of the 500 patients. *,, : $\mathrm{p}<0.05$ versus differently labelled severity groups (analysis of variance with post hoc comparisons between severity groups); ${ }^{+}: \mathrm{p}<0.05$ overall association between severity and the patient characteristic (Chi-squared test for homogeneity).

Table 2. - Patient-reported symptoms during the past 14 days by asthma severity grade

\begin{tabular}{|c|c|c|c|c|}
\hline & Intermittent & $\begin{array}{c}\text { Mild } \\
\text { persistent }\end{array}$ & $\begin{array}{l}\text { Moderate } \\
\text { persistent }\end{array}$ & $\begin{array}{c}\text { Severe } \\
\text { persistent }\end{array}$ \\
\hline Subjects $n$ & 174 & 134 & 153 & 39 \\
\hline$\geqslant 1$ night waking up because of asthma $\%$ & $10.9^{\#}$ & $43.3^{\#}$ & $59.5^{\#}$ & $76.9^{\#}$ \\
\hline Nights woken up nights & $0.19 \pm 0.66^{*}$ & $1.26 \pm 2.07 *$ & $3.13 \pm 4.03^{*}$ & $7.18 \pm 5.8^{*}$ \\
\hline$\geqslant 1$ day with daytime symptoms $\%$ & $45.4^{\#}$ & $79.1^{\#}$ & $85.6^{\#}$ & $89.7^{\#}$ \\
\hline Days with symptoms days & $1.13 \pm 1.87 *$ & $4.33 \pm 4.39 *$ & $6.41 \pm 5.00^{*}$ & $9.33 \pm 5.31 *$ \\
\hline Symptom-free days days & $12.87 \pm 1.87$ & $9.67 \pm 4.39$ & $7.59 \pm 5.00$ & $4.67 \pm 5.31$ \\
\hline No symptoms $\%$ & $51.7^{\#}$ & $14.9^{\#}$ & $10.5^{\#}$ & $5.1^{\#}$ \\
\hline \multicolumn{5}{|l|}{ Limitations in normal daily activities because of asthma symptoms $\%$} \\
\hline Limited on rare occasions & $88.9^{\#}$ & $43.1^{\#}$ & $30.2^{\#}$ & $3.1^{\#}$ \\
\hline Slightly limited most or all of the time & $11.1^{\#}$ & $52.9^{\#}$ & $27.1^{\#}$ & $25.0^{\#}$ \\
\hline Moderately limited most or all of the time & $0.0^{\#}$ & $3.9^{\#}$ & $37.5^{\#}$ & $59.4^{\#}$ \\
\hline Severely limited most or all of the time & $0.0^{\#}$ & $0.0^{\#}$ & $5.2^{\#}$ & $12.5^{\#}$ \\
\hline \multicolumn{5}{|l|}{ Asthma exacerbations or worsening of symptoms $\%$} \\
\hline None & $52.0^{\#}$ & $12.7^{\#}$ & $9.2^{\#}$ & $2.6^{\#}$ \\
\hline Brief (lasting a few hours to a few days) & $46.2^{\#}$ & $67.9^{\#}$ & $37.9^{\#}$ & $12.8^{\#}$ \\
\hline Slight impact on sleep and activities most or all of the time & $1.7^{\#}$ & $15.7^{\#}$ & $26.1^{\#}$ & $18.0^{\#}$ \\
\hline Moderate impact on sleep and activities most or all of the time & $0.0^{\#}$ & $3.7^{\#}$ & $22.2^{\#}$ & $46.2^{\#}$ \\
\hline Major impact on sleep and activities most or all of the time & $0.0^{\#}$ & $0.0^{\#}$ & $4.6^{\#}$ & $20.5^{\#}$ \\
\hline
\end{tabular}

Data are presented as mean \pm SD unless otherwise indicated. *: $\mathrm{p}<0.05$ versus all other severity groups (analysis of variance with post hoc comparisons between severity groups); ${ }^{\#}: \mathrm{p}<0.05$ overall association between severity and the symptom (Chi-squared test for homogeneity). 
Table 3. - Patient-reported medication use during the past 14 days by asthma severity grade

\begin{tabular}{|c|c|c|c|c|}
\hline & Intermittent & Mild persistent & Moderate persistent & Severe persistent \\
\hline Subjects $n$ & 174 & 134 & 153 & 39 \\
\hline No asthma drug therapy $\%$ & $12.1 *$ & $0.8^{*}$ & $0.0^{*}$ & $0.0^{*}$ \\
\hline \multicolumn{5}{|l|}{ Specific asthma drug therapy $\%$} \\
\hline SABA alone & $21.8^{*}$ & $17.2^{*}$ & $11.1^{*}$ & $10.3^{*}$ \\
\hline LABA alone & 4.0 & 3.7 & 1.3 & 2.6 \\
\hline $\mathrm{SABA}+\mathrm{LABA}^{\#}$ & 0.0 & 4.5 & 2.0 & 2.6 \\
\hline SABA+ICS & $1.7 *$ & $11.2 *$ & $13.7 *$ & $5.1^{*}$ \\
\hline $\mathrm{LABA}+\mathrm{ICS}$ & $10.3^{*}$ & $17.2^{*}$ & $18.3^{*}$ & $7.7^{*}$ \\
\hline $\mathrm{SABA}+\mathrm{LABA}+\mathrm{ICS}$ & $2.3^{*}$ & $11.2^{*}$ & $15.0^{*}$ & $12.8^{*}$ \\
\hline $\mathrm{ICS}^{\top}$ & $35.1 *$ & $66.4^{*}$ & $75.2^{*}$ & $64.1^{*}$ \\
\hline Low-dose ${ }^{+}$ICS & 54.1 & 36.0 & 21.7 & 16.0 \\
\hline Medium-dose $^{+}$ICS & 36.1 & 42.7 & 31.3 & 16.0 \\
\hline High-dose $^{+}$ICS & 9.8 & 21.3 & 47.0 & 68.0 \\
\hline LTRA & 10.9 & 13.4 & 12.4 & 15.4 \\
\hline Oral corticosteroids & $4.0^{*}$ & $5.2^{*}$ & $15.7^{*}$ & $33.3^{*}$ \\
\hline Nasal corticosteroids & 29.9 & 34.3 & 28.8 & 18.0 \\
\hline Antihistamines & 27.0 & 21.6 & 19.6 & 15.4 \\
\hline Antibiotics & 6.3 & 3.7 & 4.6 & 0.0 \\
\hline Allergen immunotherapy & 15.6 & 10.4 & 6.5 & 2.5 \\
\hline Alternative medicine & 2.3 & 3.7 & 1.3 & 5.1 \\
\hline
\end{tabular}

SABA: short-acting $\beta_{2}$-agonist (inhaled); LABA: long-acting $\beta_{2}$-agonist (inhaled); ICS: inhaled corticosteroids; LTRA: leukotriene receptor antagonist. ${ }^{\#}$ : without other drugs; ": in any dose or combination; ${ }^{+}$: Global Initiative for Asthma recommended ICS dose levels [12]. *: p<0.05 overall association between severity and the medication use (Chi-squared test for homogeneity).

Table 4. - Patient-reported healthcare resource use during the past year by asthma severity grade

\begin{tabular}{|c|c|c|c|c|}
\hline & Intermittent & Mild persistent & Moderate persistent & Severe persistent \\
\hline Subjects $n$ & 174 & 134 & 153 & 39 \\
\hline General practitioner visits & $3.1 \pm 5.7^{*} ; 0$ & $4.8 \pm 8.6^{*, \#} ; 2$ & $6.2 \pm 12.6^{\#, \oplus ; 2}$ & $8.6 \pm 12.0^{\oplus ; 6}$ \\
\hline Other physician visits & $3.5 \pm 3.7 ; 2$ & $4.5 \pm 5.5 ; 2$ & $4.3 \pm 6.4 ; 2$ & $4.7 \pm 4.5 ; 4$ \\
\hline$\geqslant 1$ emergency department visits $\%$ & 6.3 & 14.9 & 21.6 & 38.5 \\
\hline Emergency department visits & $0.10 \pm 0.43 * ; 0$ & $0.44 \pm 2.31 * ; 0$ & $0.51 \pm 1.24 * ; 0$ & $1.41 \pm 3.1^{\#} ; 0$ \\
\hline$\geqslant 1$ hospitalisations $\%$ & 3.5 & 6.7 & 8.5 & 33.3 \\
\hline Hospitalisations & $0.03 \pm 0.18 * ; 0$ & $0.16 \pm 0.1 * ; 0$ & $0.12 \pm 0.57 * ; 0$ & $0.46 \pm 0.76^{\#} ; 0$ \\
\hline
\end{tabular}

Data are presented as mean $\pm \mathrm{SD}$; median unless otherwise indicated. ${ }^{*},{ }^{*},{ }^{\top}: \mathrm{p}<0.05$ versus differently labelled severity groups (analysis of variance with post hoc comparisons and Kruskal-Wallis test between severity groups).

Table 5. - Patient-reported productivity loss during the past year by asthma severity grade

\begin{tabular}{lcccc}
\hline & Intermittent & Mild persistent & Moderate persistent & Severe persistent \\
\hline Subjects & 174 & 134 & 153 & 39 \\
Paid workdays lost & $4.1 \pm 13.0^{*} ; 0$ & $4.8 \pm 12.1^{*} ; 0$ & $7.5 \pm 20.6^{*} ; 0$ & $17.7 \pm 37.6^{\#} ; 0$ \\
Unpaid work days lost $_{\text {Effectiveness }}^{+}$at paid work & $3.1 \pm 12.7 ; 0$ & $4.0 \pm 14.4 ; 0$ & $4.8 \pm 15.4 ; 0$ & $7.4 \pm 27.4 ; 0$ \\
Satisfaction $^{\S}$ with treatment & $76.4 \pm 23.8^{*} ; 83.0$ & $73.0 \pm 24.3^{*}, \# ; 7.5$ & $66.1 \pm 27.9^{\#} ; 71.0$ & $56.0 \pm 34.2^{\ddagger} ; 57.0$ \\
\hline
\end{tabular}

Data are presented as mean $\pm \mathrm{SD}$; median unless otherwise indicated. ${ }^{+}:$visual analogue scale (VAS) of 0 (totally ineffective)-100 (normal effectiveness); ${ }^{\S}$ : VAS of 0 (completely dissatisfied)-100 (completely satisfied). ${ }^{*},{ }^{\#},{ }^{\uparrow}: \mathrm{p}<0.05$ versus differently labelled severity groups (analysis of variance with post hoc comparisons and Kruskal-Wallis test between severity groups).

resource utilisation and the cost of asthma in Italy [20, 21, 24] and other European countries [3, 6, 7, 25, 26].

Physician-classified asthma severity, using the GINA classification, is clearly associated with patient-reported symptomatology and resource use. Even though the present sample comprised only $7.8 \%$ of patients with severe persistent asthma, this small group incurred $20.6 \%$ of total costs. Conversely, the $34.8 \%$ of patients with intermittent asthma consumed only $19.9 \%$ of resources (fig. 2 ).

It is difficult to compare absolute costs, or even the association between asthma severity and costs, across studies. This is because of differences in methodology and because most previous studies employed a three-category disease grading (mild, moderate and severe asthma), whereas, in the present study, patient classification was based on the international GINA guideline. In spite of these limitations, a consistent pattern of asthma cost emerges: the total cost per year ratio between an average patient in the lowest severity group and a patient in the highest group was 1:4.6 in the present study (fig. 1). This ratio is lower than that from a cohort of asthma patients in France [7], but almost identical to the 1:4.8 ratio reported for a population of asthma patients in Spain [6], and very close to the 1:4.1 [23] and 1:4.0 ratios [20] also reported from Italy. 


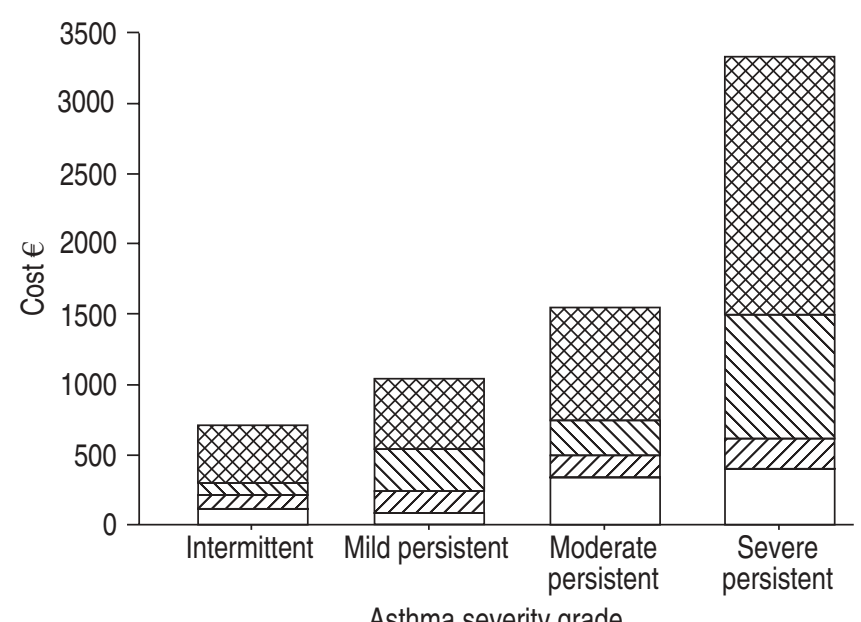

Asthma severity grade

Fig. 1. - Asthma-related direct ( $\square$ : drug; $\mathbb{Z}$ : physician; $\mathbb{\mathbb { N }}$ : emergency department and hospitalisation) and indirect ( annual costs per patient by asthma severity grade.

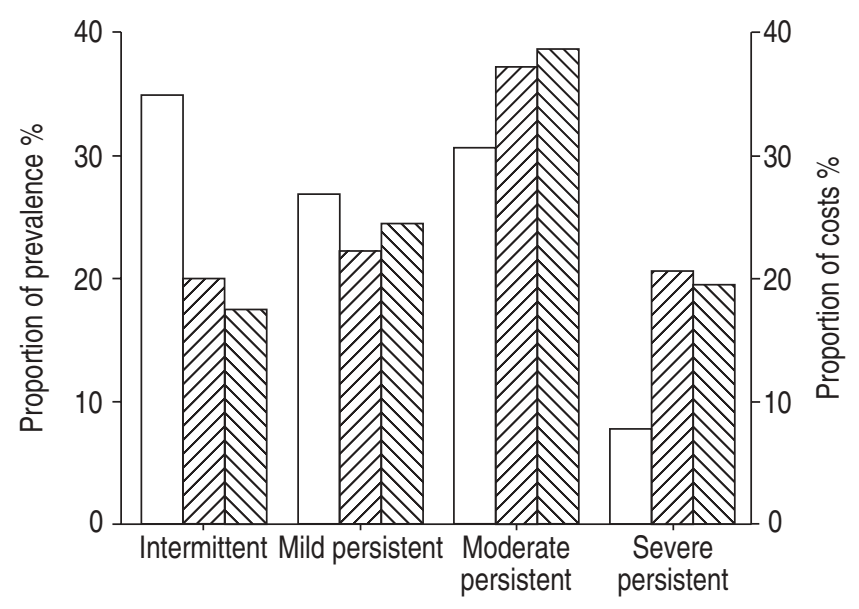

Asthma severity grade

Fig. 2. - Relationship between asthma severity grade and costs ( $\mathbb{Z}$ : total costs; $\mathbb{\mathbb { N }}$ : direct costs; $\square$ : prevalence).

Taken together, these studies establish that a disproportionately large fraction of the total disease cost is generated by a relatively small fraction of patients with severe symptoms [6]. These unfavourable clinical and economic consequences may be preventable to some extent. There is ample evidence that, despite the availability of effective therapies, asthma control is suboptimal for many patients in former Western Europe, including Italy, with management falling short of the goals in the GINA guidelines [27].

Assessment of asthma control or quality of management was not an aim of the present study, but the results pertaining to symptomatology and drug utilisation, summarised in tables 2 and 3, seem to confirm the above observation for the present patient population. Comparison of the GINA recommendations [12] and the present results regarding daytime and night-time symptoms, limitations in daily activities and emergency department visits indicates poor control of asthma. The degree of inadequate control was associated with the level of severity (table 2), and is in broad agreement with that described across former Western Europe [27].
Only those patients classified as having "intermittent" asthma appeared reasonably, although not perfectly, well controlled. It was surprising to find that $35.1 \%$ of these patients received inhaled corticosteroids (table 3 ). This is not in agreement with GINA guidelines, and may indicate overtreatment of this patient group. An alternative interpretation would be false assessment of asthma severity level on the part of the physicians; conceivably, some of these patients might have fallen into a higher severity category, based on their underlying pathophysiology [28], but were well controlled at the time of assessment and, therefore, "upgraded". This illustrates how assessment of severity level is inextricably confounded by level of control [28].

Suboptimal management may be at least one of the causes of the poor level of control in the present patients classified as moderate or severe persistent; 11.1 and $10.3 \%$ of these groups were managed using short-acting $\beta_{2}$-agonists alone, and only 75.2 and $64.1 \%$ were on inhaled corticosteroids (table 3 ). This is not in agreement with international guidelines [12], and must be considered undertreatment. Even though utilisation of inhaled corticosteroids in the present high-severity patient groups was better than that in a previous survey [27], a recent study reported inhaled corticosteroid treatment in $96 \%$ and $90 \%$ of patients with moderate and severe persistent asthma managed according to best practice guidelines [7]. In addition, a recent study by PoLuZzI et al. [29] suggested that inhaled corticosteroids were underused, which is in line with the present findings.

It cannot be speculated, on the basis of this or other noncomparative studies, what the savings are that might be realised through improved asthma control. There are indications that even optimal management will not result in full control of asthma in all patients [7]. However, given the strong association between symptom-based grade and costs, the savings potential accrued from improvement in asthma management may be considerable from a societal, patient and payer perspective. Moreover, improved management would also be expected to reduce intangible costs such as poor effectiveness at work, and increase patient satisfaction with treatment and quality of life.

The main cost drivers of asthma in the present study were indirect costs and emergency service, and hospitalisation costs. Together, these three components accounted for $72 \%$ of the mean total cost per patient in the present sample. The corresponding figures from two other Italian-based surveys were $72.2 \%$ [21] and $56 \%$ [20]. In contrast, outpatient prescribed medication was not a dominant cost factor in asthma care in the present patient sample, accounting for $16 \%$ and $33 \%$ of total costs and direct medical costs, respectively. Again, this is in good agreement with the corresponding figures of $24 \%$ and $33 \%$ from another Italian study by LUCIONi et al. [20]. MAssimetTi et al. [21] conducted a population-based survey and reported drug costs as accounting for only $14 \%$ of total asthma costs in Italy.

Similar or almost identical estimates have been calculated for other countries, including Spain [6] and France [14], but some cost-of-asthma analyses found that prescription medicines made up more than $50 \%$ of all direct costs $[15,25,26]$. To some extent, these differences may be explained by methodological factors. For example, WeIssfLoG et al. [26] reported that outpatient prescribed medicines accounted for $55 \%$ of direct asthma costs in Germany, but did not include outpatient physician services in the calculation, due to a lack of adequate data. Elimination of this cost component will probably have resulted in overestimation of the other components. However, true differences across countries must be expected to result from differences in healthcare utilisation such as prescription rates per patient [9] and cost structures, particularly wage levels, which may influence physician and 
hospitalisation costs $[15,25]$. Such variability limits generalisation of the present results to other healthcare environments. In spite of this caveat, it is interesting to observe that the mean direct cost of asthma in the present study is very similar to findings from at least one other country: VAN GANSE et al. [14] recently reported mean direct medical costs of $€ 721$ in a large cohort of asthma patients of GINA severity levels $2-4$, treated in the French healthcare system. This figure is in close agreement with the $€ 600$ found in the present survey, given the fact that the present sample also included a sizeable fraction of GINA level 1 patients.

A number of methodological aspects of the present study merit discussion. The present study was based on a specifically designed questionnaire with a short recall period for most outcomes surveyed. This allowed for the assessment of variables such as effectiveness of paid work, or quality of life-associated symptoms, which cannot be measured by retrospective chart review [3] or medical claims data [25, 26, 30].

Outcome assessments from the present study are also probably more relevant than those from studies in which patients are surveyed at the time of an index event (e.g. new prescription), and where severity of disease symptoms and, consequently, healthcare consumption may be unusually high [30].

However, the present findings related to the indirect cost of asthma may be subject to at least two sources of bias. First, the present calculations are based exclusively on paid workdays lost. This conservative approach appeared warranted since there are no official or widely accepted figures regarding valuation of unpaid work in Italy, and the instrument used for assessing loss of effectiveness at paid work had not been validated in this setting. This implies that workdays lost by, for example, students or homemakers remain unaccounted for, as is loss of effectiveness at work due to asthma. This source of bias tends to underestimate the true indirect cost of asthma per patient in Italy. Inspection of the data in table 5 shows that the present estimate of indirect costs might almost double when these factors are included in the cost calculation.

Secondly, the patient selection criteria specified an upper age limit of 55 yrs. This was designed to minimise erroneous inclusion of patients with COPD, the prevalence of which increases with age [31]. Although this is a broader age limit than was selected for other similar studies [14, 32], most retired persons and those with serious comorbidity, who might also have left the workforce, were excluded. This selection may inflate the present overall estimate of indirect costs per patient by over-representing adult asthma patients who are still in the active work force. Conversely, the patient sample may not have picked up indirect costs from early retirement as a result of asthma, which was reported to be a relevant economic factor in at least one study [26]. The impact on the present results of these factors is difficult to gauge, but will probably not affect overall conclusions regarding the relationship between healthcare resource use and asthma severity.

How representative of the Italian adult patient population with asthma is the present sample? Even though the proportion of patients who declined to participate in the study was small, the patient group clearly represents a convenience sample and this may thus limit extrapolation of study findings. Moreover, the study was limited to specialist clinics, excluding GPs. This might have biased the present observations towards higher-than-representative levels of resource utilisation and costs, since patient populations seen by GPs and specialist clinics are not neccessarily comparable. However, $59 \%$ of patients were studied during their first specialist visit, immediately after referral from a GP, and data gathered on that occasion probably reflect the level of care provided by GPs. Moreover, a recent population-based survey showed that the majority of Italian asthma patients are in the care of specialists rather than GPs, and, more importantly, that the ratio of GP-treated to specialist-treated patients is consistent across the levels of asthma control [32]. This scenario may be different from other healthcare environments and could be explained by the cost structure of the Italian health service, which facilitates access to specialists by patients across the entire disease spectrum. Although differences in absolute levels of resource utilisation or costs associated with the different groups of providers cannot be excluded, the ratios across severity groups are probably not biased by the selection of specialists alone. Moreover, the sex distribution, level of comorbidity and relative distribution of severity level in the present patient sample are comparable to those in previously described cohorts of asthma patients [7, 13, 33]. Therefore, the present observations may not lend themselves to extrapolation of the total cost of asthma in Italy, but are reflective of the association between severity and resource utilisation and cost in the large segment of patients who are seen by specialists.

In conclusion, the present results emphasise the importance of asthma severity evaluated by GINA guidelines as a predictor of symptoms, limitations in normal daily activities, medical resource utilisation, and both direct and indirect costs. With current patterns of treatment, a large proportion of patients continue to experience daytime and night-time symptoms and are limited in their daily activities.

The present data suggest that some patients, particularly those in the high-severity groups, are undertreated according to Global Initiative for Asthma guidelines. Evidence has shown that consistent asthma control, which can be achieved with various novel treatments, may reduce the overall costs of asthma even though the medication cost component increases.

\footnotetext{
Acknowledgements. The authors wish to thank M.B. Bilò, S. De Luca, G.P. Facchini and B. Farabollini, Dept of Respiratory and Allergic Diseases, Umberto I Hospital, Ancona; L. Dutto, Dept of Biomedical Sciences and Human Oncology, University of Turin, Turin; M. Banfi, Division of Pulmonary Disease, Institute for Care and Research, Scientific Institute of Rehabilitation, Salvatore Maugeri Foundation, Tradate; A. D'Intino, Division of Pulmonary Disease, General Hospital Chieti, Chieti; P. Bonadonna, Allergy Unit, General Hospital Verona, Verona; M.P. Forciniti, Allergy Unit, General Hospital Pesaro, Pesaro; A Calcagni, Respiratory Unit, General Hospital Fermo, Fermo; G. Allevi, Respiratory Unit, General Hospital Ascoli Piceno, Ascoli Piceno; F. Tubaldi, Respiratory Unit, General Hospital Macerata, Macerata; D. Macchia, F. Fossi and L. Emmi, Dept of Internal Medicine, University of Florence, Florence; C. Politi, Dept of Internal Medicine, General Hospital Pozzuoli, Pozzuoli; F. Giannoccaro and G. Munno, Dept of Internal Medicine, General Hospital Monopoli, Monopoli; and W. D'Angelillo, Division of Pulmonary Disease, General Hospital Reggio di Calabria, Reggio di Calabria, Italy, for their invaluable help in collecting data for the present study.
}

\section{References}

1. Skjonsberg $\mathrm{OH}$, Clenchaas $\mathrm{J}$, Leegaard $\mathrm{J}$, et al. Prevalence of bronchial asthma in schoolchildren in Oslo, Norway - comparison of data obtained in 1993 and 1981. Allergy 1995; 50: 806-810. 
2. Weiss KB, Sullivan SD. The health economics of asthma and rhinitis. I. Assessing the economic impact. J Allergy Clin Immunol 2001; 107: 3-8.

3. Szucs TD, Anderhub H, Rutishauser M. The economic burden of asthma: direct and indirect costs in Switzerland. Eur Respir J 1999; 13: 281-286.

4. Tirimanna PRS, van Schayck CP, den Otter JJ, et al. Prevalence of asthma and COPD in general practice in 1992: has it changed since 1977? Br J Gen Pract 1996; 46: 277-281.

5. Weiss KB, Sullivan SD, Lyttle CS. Trends in the cost of illness for asthma in the United States, 1985-1994. J Allergy Clin Immunol 2000; 106: 493-469.

6. Serra-Batlles J, Plaza V, Morejon E, Comella A, Brugues J. Costs of asthma according to the degree of severity. Eur Respir J 1998; 12: 1322-1326.

7. Godard P, Chanez P, Siraudin L, Nicoloyannis N, Duru G. Costs of asthma are correlated with severity: a 1-yr prospective study. Eur Respir J 2002; 19: 61-67.

8. Janson C, Anto J, Burney P, et al., on behalf of the European Community Respiratory Health Survey II. The European Community Respiratory Health Survey: what are the main results so far? Eur Respir J 2001; 18: 598-611.

9. Cerveri I, Locatelli F, Zoia MC, Corsico A, Accordini S, De Marco R. International variations in asthma treatment compliance. Eur Respir J 1999; 14: 288-294.

10. Cerveri I, Zoia MC, Bugiani M, et al. Inadequate antiasthma drug use in the north of Italy. Eur Respir J 1997; 10: 27612765.

11. Cazzoletti L, Bugiani M, Ferrari M. Il carico socioeconomico dell'asma ed il controllo dei sintomi in giovani adulti, $\mathrm{i}$ risultati di uno studio multicentrico italiano. In: G. Gallo, G. Signorello, eds. La Salute tra Società e Prova Scientifica. Atti del $\mathrm{I}^{\circ}$ Congresso della Società Italiana di Statistica Medica ed Epidemiologia Clinica. Naples, 2001; pp. 244 277.

12. Global Initiative for Asthma. Global Strategy for Asthma Management and Prevention. 2002 Revision. National Institutes of Health, National Heart, Lung, and Blood Institute. www.ginasthma.com/workshop.pdf. Date updated: April 2002. Date accessed: 13 November 2002.

13. Liard R, Leynaert B, Zureik M, Beguin F-X, Neukirch F. Using Global Initiative for Asthma guidelines to assess asthma severity in populations. Eur Respir $J$ 2000; 16: 615620.

14. Van Ganse E, Laforest L, Pietri G, et al. Persistent asthma: disease control, resource utilisation and direct costs. Eur Respir J 2002; 20: 260-267.

15. Herjavecz I, Nagy GB, Gyurkovits K, et al. Cost, morbidity, and control of asthma in Hungary: the Hunair study. $J$ Asthma 2003; 40: 673-681.

16. Vollmer WM, Markson LE, O'Connor E, Frazier EA, Berger M. Association of asthma control with health care utilization. Am J Respir Crit Care Med 2002; 165: 195-199.
17. Anon. L'Informatore Farmaceutico. Edizioni OEMF. Rome, 1999.

18. Ministero della Sanità. Nomenclatore tariffario delle prestazioni ambulatoriali DM 22.07.96. Gazetta Ufficiale No. 216. 14.09.1996.

19. Ministero della Sanità. Aggiornamento delle tariffe delle prestazioni di assistenza ospedaliera di cui al DM 14.12.1994; DM 30.06.97. Supplemento Ordinario Gazetta Ufficiale No. 209. 08.09.1997.

20. Lucioni C, Mazzi S, Serra G, Vaghi A. Il costo sociale dell'asma nell'adulto, in Italia. Rass Pat App Resp 2001; 16: 90-103.

21. Massimetti MM, Bonzanini A, Avossa R, Berto P, Gianfrate F. Il costo dell'asma in Italia. Giornale di Farmacoeconomia 1999; 3: 57-64

22. Dal Negro R, Turco C, Micheletto C. I costi sociali dell'asma bronchiale. Farmacoeconomia 1995; 2: 16-22.

23. Berto P, Degli Esposti E, Buda S. Cost of Italian hypertensive patient: a feasibility study from the Pandora project. Value Health 1998; 1: 32 (abstract CVB1).

24. Dal Negro R, Berto P, Tognella S, Quareni L. Cost-of-illness of lung disease in the TriVeneto region, Italy: the GOLD study. Monaldi Arch Chest Dis 2002; 57: 3-9.

25. Kiivet RA, Kaur I, Lang A, Aaviksoo A, Nirk L. Costs of asthma treatment in Estonia. Eur J Public Health 2001; 11: 89-92.

26. Weissflog D, Matthys H, Virchow JC. Epidemiology and costs of bronchial asthma and chronic bronchitis in Germany. Dtsch Med Wochenschr 2001; 126: 803-808.

27. Rabe KF, Vermeire PA, Soriano JB, Maier WC. Clinical management of asthma in 1999: the Asthma Insights and Reality in Europe (AIRE) study. Eur Respir J 2000; 16: 802807.

28. Vollmer WM, Markson LE, O'Connor E, et al. Association of asthma control with health care utilization and quality of life. Am J Respir Crit Care Med 1999; 160: 1647-1652.

29. Poluzzi E, Resi D, Zuccheri P, et al. Use of Anti-asthmatic drugs in Italy: analysis of prescriptions in general practice in the light of guidelines for asthma treatment. Eur $J$ Clin Pharmacol 2002; 58: 55-59.

30. Klingman D, Bielory L, Wang Y, et al. Asthma outcome changes associated with use of the leukotriene-receptor antagonist zafirlukast. Manag Care Interface 2001; 14: 6266.

31. Rees J, Calverly PMA. Handbook of Chronic Obstructive Pulmonary Disease. London, Martin Dunitz, 2002.

32. DeMarco R, Bugiani M, Cazzoletti L, et al. The control of asthma in Italy. A multicentre descriptive study on young adults with doctor diagnosed current asthma. Allergy 2003; 58: $221-228$

33. Bousquet J, ARIA Workshop Group. Allergic rhinitis and its impact on asthma. Comorbidity and complications. J Allergy Clin Immunol 2001; 103: Suppl., S171. 